\title{
UMA ANÁLISE DA RELAÇÃO ENTRE TECNOLOGIA NO LOCAL DE TRABALHO E RENDIMENTOS NO BRASIL
}

\author{
Mauricio Cortez Reis * \\ Antonio Marcos Hoelz Pinto Ambrozio ${ }^{\dagger}$ \\ Danielle Carusi Machado ${ }^{\ddagger}$
}

\begin{abstract}
Resumo
Diferenças na qualidade dos postos de trabalho podem estar associadas, pelo menos em parte, aos elevados níveis de desigualdade de rendimentos observados entre os trabalhadores no Brasil. Este artigo procura analisar a relação entre rendimentos no mercado de trabalho e uma medida do nível de tecnologia disponível no posto, e as implicações dessa relação para a desigualdade de rendimentos no Brasil. Usando dados do suplemento sobre inovação tecnológica da PNAD (Pesquisa Nacional por Amostra de Domicílios) de 2005 e 2008, são encontradas evidências de que trabalhadores com acesso a novas tecnologias no local de trabalho recebem rendimentos substancialmente mais elevados, mesmo em setores onde não se espera que a tecnologia tenha um impacto direto expressivo sobre a produtividade. Os resultados sugerem que disparidades na qualidade dos postos de trabalho podem ser importantes na determinação da distribuição de rendimentos do trabalho.
\end{abstract}

\begin{abstract}
Part of the high level of earnings inequality verified among workers in Brazil could be associated with differences in the quality of jobs. This paper analyzes the relationship between labor earnings and a measure of the technology available in the workplace and the implications of this relationship to earnings inequality in Brazil. Using data from the supplement on technological innovation in the 2005 and 2008 PNAD (National Household Sample Survey), the results show that workers with access to new technologies in the workplace receive higher earnings, even in sectors where technology should not affect productivity. Evidence suggests that disparities in the quality of jobs may have an important role on the distribution of labor earnings in Brazil.
\end{abstract}

Palavras-chave: Diferencial de rendimentos, tecnologia.

JEL classification: J3, J0

\footnotetext{
* IPEA.

+ BNDES.

‡ Faculdade de Economia da Universidade Federal Fluminense.
} 


\section{Introdução}

Os rendimentos do trabalho no Brasil são distribuídos de maneira bastante desigual, como mostram diversos artigos na literatura (ver, por exemplo, Mendonça \& R. (1995)). Diferenças no nível educacional são geralmente identificadas como principais responsáveis por esse elevado patamar da desigualdade de rendimentos. Pode-se argumentar, porém, que trabalhadores mais escolarizados não apenas devem ser mais produtivos, como também devem ocupar postos de trabalho de melhor qualidade. Essas diferenças na qualidade dos postos de trabalho, por sua vez, podem ser representadas em parte pelas tecnologias disponíveis para o trabalhador, que podem contribuir para aumentar a sua produtividade e, conseqüentemente, os seus rendimentos. Além disso, trabalhadores com acesso a novas tecnologias podem não apenas estar alocados em postos de trabalho de melhor qualidade, como também possuírem determinadas características não observadas que influenciam diretamente a sua produtividade.

Este artigo tem como objetivo analisar a relação existente entre os rendimentos no mercado de trabalho e uma medida do nível de tecnologia disponível no posto de trabalho e as implicações da relação entre essas duas variáveis para a desigualdade de rendimentos no Brasil.

O impacto de novas tecnologias na estrutura salarial é um assunto que vem sendo bastante discutido na literatura econômica, principalmente com o aumento observado no diferencial salarial por qualificação nos Estados Unidos a partir do final da década de setenta. Como indivíduos mais qualificados tendem a ser mais capacitados para operar equipamentos modernos, a difusão no uso de computadores e de tecnologias avançadas teria contribuído para aumentar a demanda por esse tipo de trabalhador em relação aos indivíduos com níveis mais baixos de qualificação (Bound (1992); Murphy \& K. (1992); e Autor $(1999))^{1}$. Autor et al. (1998) sugerem, a partir de dados inter-industriais, que a maior difusão no uso de computadores pode explicar boa parte do crescimento na participação de trabalhadores mais qualificados no emprego.

Uma parte dessa literatura procura analisar especificamente a associação entre a utilização de computadores e as remunerações no mercado de trabalho. De acordo com Krueger (1993), os trabalhadores que usam computadores recebem salários entre $10 \%$ e $15 \%$ maiores do que os trabalhadores com características semelhantes que não utilizam essa tecnologia nos Estados Unidos. Além disso, são apresentadas evidências de aumento nesse prêmio salarial ao longo do tempo. DiNardo \& Pischke (1997) e Entorf \& Kramarz (1997), entretanto, mostram que esse diferencial pode ser atribuído a fatores nãoobservados e não necessariamente ao efeito do uso de computadores sobre a produtividade.

Podem ser encontrados na literatura diversos resultados mostrando que a utilização de computadores está associada a rendimentos mais elevados. Utilizando dados em painel para o Reino Unido, Bell (1996) encontra um prêmio pelo uso de computador correspondente a 13\%, mesmo controlando para a heterogeneidade individual. Oosterbeek (1997) estima um prêmio de $12 \%$ na

\footnotetext{
${ }^{1}$ Além do progresso tecnológico, outros fatores usualmente citados para explicar o aumento no diferencial salarial por qualificação são: a maior abertura comercial que implicou em redução da demanda por trabalhadores menos qualificados nos países desenvolvidos, a desaceleração na oferta de trabalhadores mais educados e os fatores institucionais, como, por exemplo, a perda de influência dos sindicatos e a redução do salário mínimo.
} 
Holanda, enquanto Miller \& Mulvey (1997) obtem um diferencial entre 12 e $16 \%$ na Austrália. A relação entre utilização de computadores e rendimentos parece bem mais acentuada para países em desenvolvimento. Sakkelariou \& Patrinos (2004) analisam o caso de trabalhadores qualificados no Vietnam. O diferencial entre os indivíduos que usam computador no trabalho e os que não usam é de $110 \%$. Adicionando diversos controles para características dos trabalhadores e dos postos de trabalho, o diferencial diminui para $26 \%$. Os autores também mostram que indivíduos com treinamento para operar computadores, mas que não usam essa tecnologia, apresentam um prêmio em relação aos que não possuem tal qualificação. Porém, o prêmio é muito mais elevado para aqueles que utilizam computador no trabalho e possuem qualificação para tal.

O progresso tecnológico mais acelerado parece ter implicações importantes para o comportamento da distribuição de rendimentos do trabalho como um todo. Autor et al. (2006) argumentam que a difusão no uso de computadores pode explicar um processo de polarização no mercado de trabalho americano, com o aumento do diferencial salarial entre indivíduos na cauda superior da distribuição salarial em relação à mediana nos últimos 25 anos, e uma recente redução da diferença entre o salário da mediana e o dos trabalhadores na cauda inferior desta distribuição.

Os resultados de alguns estudos para o Brasil também sugerem que ocorreram mudanças na estrutura do mercado de trabalho na década de noventa, com aumentos no prêmio por maior escolaridade e crescimento na taxa de desemprego, principalmente para os trabalhadores menos qualificados. Essas alterações podem estar relacionadas à expansão no uso de tecnologias mais avançadas desde a liberalização comercial, no início da década noventa, e o consequente aumento na demanda por trabalhadores mais qualificados. Menezes Filho \& Rodrigues (2003) mostram que a maior utilização de tecnologias modernas, medidas pela intensidade em $P \mathcal{E} D$ nos setores da indústria, levou a um aumento na demanda por trabalhadores mais qualificados nos anos noventa. Em artigo mais recente, Menezes Filho (2006) também apresenta evidências consistentes com a ocorrência de choques tecnológicos enviesados para trabalhadores qualificados no período $1996-2002^{2}$.

Neste artigo, analisamos a relação entre o acesso a novas tecnologias no local de trabalho e rendimentos no Brasil, utilizando dados do suplemento da PNAD (Pesquisa Nacional por Amostra de Domicílios) de 2005 e de 2008. Essa pesquisa oferece informações, com representatividade nacional, sobre o uso de internet no local de trabalho e no domicílio. A utilização de internet no trabalho, que na maioria dos casos implica no uso de computador, é então empregada como proxy para o acesso do trabalhador a tecnologias mais modernas. A abordagem econométrica consiste em estimar a relação entre a utilização dessas tecnologias e os rendimentos do trabalho, assim como as implicações dessa associação para a distribuição de rendimentos entre os trabalhadores.

Os resultados sugerem que trabalhadores com acesso a tecnologias mais modernas no local de trabalho recebem, em média, rendimentos substancialmente mais elevados do que os trabalhadores sem acesso a essas tecnologias.

\footnotetext{
${ }^{2}$ Nesse último trabalho são utilizadas como proxies de intensidade em tecnologia, além do investimento em $\mathrm{P} \& \mathrm{D}$, outras variáveis como participação de insumos importados na firma, registro de patentes e indicadores para firma exportadora e para firma que inova em processos ou produtos.
} 
Embora não seja possível estabelecer uma relação de causalidade entre o uso de tecnologias e o nível dos rendimentos, esses mesmos resultados são verificados para a maioria dos setores e das ocupações separadamente, e os diferenciais de rendimento continuam significativos mesmo quando se controla por atributos produtivos observáveis do trabalhador, como educação e experiência (idade). As evidências também indicam que diferenças no acesso a novas tecnologias, e possivelmente na qualidade dos postos de trabalho, estão bastante associadas a disparidades de rendimentos no mercado de trabalho brasileiro.

$\mathrm{O}$ artigo está estruturado da seqguinte forma. A seção 2 descreve a base de dados utilizada e apresenta uma análise descritiva comparando trabalhadores que tiveram acesso a novas tecnologias no trabalho com os que não tiveram. Na seção 3 é discutida a estratégia empírica e são reportados os resultados estimados. A seção 4 apresenta as principais conclusões do artigo.

\section{Base de dados e análise descritiva}

A base de dados utilizada vem do suplemento da Pesquisa Nacional por Amostra de Domicílios (PNAD/IBGE) de 2005 e de 2008, que investiga as características de acesso às novas tecnologias de informação, como internet, computador e aparelho celular para todas as pessoas entrevistadas com idade superior a 10 anos. Nesse suplemento, indivíduos ocupados informam se usaram internet no local de trabalho no período de 3 meses antes da entrevista. A utilização de internet geralmente implica na disponibilidade de computador no trabalho, embora não necessariamente isso seja verdade. Além disso, não é possível verificar se essas tecnologias são usadas em atividades produtivas. Krueger (1993) tem um problema semelhante, pois a variável de interesse na sua análise se refere apenas ao uso direto de computador, sem especificação da finalidade.

A PNAD coleta informações de cerca de 400 mil pessoas, moradoras de aproximadamente 140 mil domicílios. Neste artigo, para os dois anos analisados, utilizamos uma sub-amostra formada por todos os indivíduos com idade maior ou igual a 21 anos e inferior a 65 anos. Além disso, a amostra é limitada a todas as pessoas ocupadas. ${ }^{3}$ Com isso, em 2005 e 2008 totalizamos 118.686 e 123.036 observações, respectivamente.

A Tabela 1 mostra as principais características dos trabalhadores na amostra, divididos segundo o uso da internet no trabalho. Em 2005, cerca de 16\% dos indivíduos declararam ter usado internet no local de trabalho nos três meses anteriores à realização da pesquisa. No ano de 2008, este percentual aumentou para $20,2 \%$.

O rendimento médio dos trabalhadores que usaram internet no trabalho é muito mais elevado do que o dos trabalhadores que não utilizaram esta tecnologia. Para o primeiro grupo, o rendimento médio por hora era de $\mathrm{R} \$ 14,35$, em 2005, enquanto o do segundo grupo era de apenas $\mathrm{R} \$ 4,17$. Em 2008, este diferencial cai ligeiramente, os que usam internet passaram a ganhar $\mathrm{R} \$ 14,01$, e os demais $\mathrm{R} \$ 4,61$. Desse modo, o acesso a computador e internet no local de trabalho chega a estar associado a um diferencial de rendimentos da ordem de quase $250 \%$.

\footnotetext{
${ }^{3}$ Fazemos alguns ajustes adicionais: a eliminação das pessoas cuja condição na família era empregado doméstico, parente de empregado doméstico ou pensionista e dos trabalhadores cuja jornada de trabalho semanal era inferior a 10 horas semanais.
} 
O Gráfico 1, que mostra a distribuição de rendimento dos trabalhadores que usam e que não usam internet no trabalho, ilustra claramente a existência deste diferencial nos dois anos analisados. Para os primeiros, a média e a dispersão dos rendimentos é mais alta, enquanto para os segundos a média é mais baixa e os rendimentos estão mais concentrados em torno da média.

Uma parte importante do diferencial de rendimentos está relacionada às características individuais dos trabalhadores, assim como do setor e do tipo de ocupação que possuem. Os trabalhadores que usaram internet possuem, em média, mais de 12 anos de estudos, enquanto os que não usaram têm apenas cerca de 7 anos de estudos em média. Mais de 55\% dos trabalhadores que utilizaram internet no trabalho estão na faixa etária de 25 a 39 anos, enquanto entre os que não usaram a proporção nessa faixa etária é cerca de 10 pontos percentuais menor. Há um ligeiro predomínio dos homens entre os usuários de internet no trabalho, mas apenas $26 \%$ e $29 \%$ dos trabalhadores que usaram internet declararam ser de cor negra ou parda nos anos de 2005 e 2008 . Já entre os que não usaram internet no local de trabalho nos últimos três meses, os negros ou pardos representam mais de $50 \%$ do total nos dois anos analisados.

Com relação às características da ocupação, como esperado, percebe-se que é entre os que possuem as melhores formas de inserção que a probabilidade de usar internet no local de trabalho é maior. Aproximadamente metade dos trabalhadores que usaram internet tem emprego com carteira de trabalho assinada (50,6\%, em 2005 e 49,8\%, em 2008), enquanto $18,3 \%$ e 19,36\%, nos anos de 2005 e 2008 respectivamente, são funcionários públicos. Considerando os trabalhadores que não utilizaram internet, as participações de empregados com carteira e funcionários públicos diminuem para $35,2 \%$ e $7 \%$, em 2005 , e $38,5 \%$ e $7 \%$, em 2008 . Há também uma representatividade maior nos setores de construção e agricultura dos trabalhadores que não usaram internet em relação aos que utilizaram essa tecnologia. Já na administração pública, ocorre o contrário.

As pessoas que usaram internet no trabalho, em geral, também têm acesso a esta tecnologia no próprio domicílio. Como a Tabela 1 mostra, metade dos que usaram internet no trabalho declarou ter usado internet no domicílio nos últimos três meses no ano de 2005. Essa proporção era de apenas 5,6\% entre os que não usaram internet no trabalho. Já no ano de $2008,12 \%$ dos que não usaram internet no trabalho tiveram acesso a esse tipo de tecnologia em casa, enquanto entre os que utilizaram internet no trabalho o uso domiciliar cresceu para $65,6 \%$.

\section{Análise dos resultados}

\subsection{A relação entre tecnologia e rendimentos no mercado de trabalho}

Esta subseção procura descrever a relação entre utilização de internet no trabalho e rendimentos, controlando para diferenças nas características individuais e do setor e ocupação do posto de trabalho. Seguindo uma abordagem semelhante à proposta por Krueger (1993), são estimadas algumas variações da seguinte equação minceriana:

$$
\ln \left(w_{i}\right)=\alpha+\gamma \cdot C_{i}+\beta \cdot X_{i}+\epsilon_{i},
$$


onde $w_{i}$ se refere ao rendimento por hora ${ }^{4}, C_{i}$ é uma variável $d u m m y$ igual a 1 se o indivíduo acessou internet, e portanto, muito provavelmente utilizou computador no trabalho durante os últimos três meses anteriores à pesquisa da PNAD e $X_{i}$ representa as variáveis de controle. Os resultados, estimados por Mínimos Quadrados Ponderados, com os pesos determinados pela participação de cada indivíduo na população, são apresentados nas Tabelas 2 e 3, para os anos de 2005 e 2008, respectivamente.

Na primeira coluna de cada tabela, a regressão não inclui nenhuma variável de controle. De acordo com o coeficiente estimado, o uso de internet no local de trabalho está associado a um diferencial de rendimentos superior a $150 \%$ nos dois anos: $235 \%(=\exp (1,208)-1)$ em 2005 , e em $2008,184 \%$. A segunda coluna mostra o resultado da regressão quando são inseridas diversas variáveis de controle. Embora a inclusão dessas variáveis reduza o diferencial de rendimentos, este ainda é substancial. Considerando trabalhadores com os mesmo valores para educação, idade, sexo, cor, região e posição na ocupação, os que usaram internet no trabalho têm em média um rendimento/hora $63,7 \%$ maior que aqueles que não utilizaram em 2005. Em 2008, este diferencial sofreu uma redução para $56 \%$.

Nas colunas 3 a 5 são incluídos controles para o setor de atividade e para o tipo de ocupação. Nos resultados da coluna 3, adicionamos os controles para ocupações a 2 dígitos. Dessa forma, são adicionadas 45 dummies para ocupações. Na coluna 4, retiramos os controles das ocupações e inserimos 56 dummies para os setores de atividade, também definidos para o nível de 2 dígitos. Os resultados mostram que a relação entre rendimentos e acesso a computador é mais reduzida quando se controla por ocupação do que por setores de atividade. Em 2005, o diferencial de rendimentos por uso de computador se reduz para $46,2 \%$, no primeiro caso, e no segundo caso para $59,1 \%$. O diferencial vai para $42 \%$ quando se controla, respectivamente, por ocupação e setor (ver coluna 5). Em 2008, o padrão é similar, apenas os diferenciais são um pouco mais reduzidos.

Comparando os resultados estimados para o Brasil com os obtidos por Krueger (1993) para os Estados Unidos e outros estudos para países desenvolvidos, nota-se que as diferenças nos rendimentos por uso de tecnologia são substancialmente maiores no Brasil. Mesmo em relação ao Vietnam os diferenciais estimados para o Brasil são muito mais elevados. Embora a variável utilizada nesses estudos não seja igual a que usamos nas estimações, ambas estão relacionadas ao acesso a computadores no local de trabalho, mesmo que a finalidade no uso dessa tecnologia não seja muito clara na maior parte dos casos.

É importante enfatizar que os resultados apresentados nas Tabelas 2 e 3 devem ser interpretados com cautela. Trabalhadores que usam internet, ainda que semelhantes em relação às características observáveis consideradas, provavelmente são mais produtivos por conta de fatores que não estão sendo considerados na análise. Características não observáveis poderiam implicar que os trabalhadores que utilizaram internet no trabalho estariam recebendo rendimentos mais altos mesmo na ausência dessa inovação tecnológica, que estaria apenas refletindo o fato dos trabalhadores mais produtivos ocuparem os melhores postos.

\footnotetext{
${ }^{4}$ Os resultados são muito semelhantes usando os rendimentos mensais como variável dependente.
} 
A despeito disso, o fato de persistirem diferenciais salariais robustos pelo acesso ao computador no trabalho quando se controla por uma série de características produtivas observáveis, incluindo aí o setor e a ocupação do trabalhador, sugere que se pudéssemos controlar pelas características produtivas não-observáveis esse diferencial, ainda que viesse a ser reduzido, não seria eliminado, restando um papel importante para o acesso a novas tecnologias na determinação dos rendimentos do trabalho. Evidências para outros países, usando dados em painel ou proxies para as características não observáveis, por exemplo, ainda assim encontram um prêmio para aqueles que usam computador no trabalho. Os diferenciais tão elevados encontrados para o Brasil, porém, sugerem que além de um possível efeito direto de novas tecnologias sobre a produtividade, a heterogeneidade nos postos de trabalho, assim como entre os próprios trabalhadores, também deve ter um papel importante.

\subsection{Resultados por ocupações e setores de atividade}

Nesta subseção são apresentados os coeficientes estimados de regressões dos rendimentos na $d u m m y$ indicando uso de internet no trabalho separadamente para cada uma das 45 ocupações e cada um dos 56 setores de atividade. A especificação adotada corresponde à utilizada na segunda coluna da Tabela 2.

Os resultados, apresentados na Tabela 4, mostram que mesmo entre trabalhadores com ocupações semelhantes há um diferencial significativo nos rendimentos para aqueles que usaram internet no trabalho. Ademais, esse diferencial varia de forma expressiva entre as ocupações consideradas e os resultados são estatisticamente significativos na maior parte dos casos. A Figura 4 mostra os resultados de regressões não-paramétricas dos coeficientes estimados para a dummy indicando uso de internet em cada ocupação na proporção de trabalhadores com pelo menos 11 anos de estudo (com o segundo grau completo), usando o método de regressões locais (LOWESS). Como se pode notar, a relação entre essas duas variáveis é decrescente, ou seja, a relação entre rendimentos e uso de internet é mais intensa nas ocupações em que a proporção de trabalhadores qualificados é menor. Embora o processo de determinação dos rendimentos seja provavelmente diferente em cada ocupação, a diferenciação reportada na Figura 4 pode se dar pelo fato desses trabalhadores possuírem alguma qualidade extra, ou por ocuparem os melhores postos de trabalho dentro de ocupações em que a qualidade média dos postos é tipicamente baixa.

De acordo com os resultados da Tabela 5, o acesso à internet no local de trabalho está associado a diferenças nos rendimentos mesmo para trabalhadores no mesmo setor de atividade, e essa relação é bastante heterogênea entre os setores. Um ponto importante sobre os resultados da Tabela 5 é que em 2005 quase todos os setores cujo coeficiente do uso de internet é inferior a 0,4 (correspondendo a um diferencial de rendimento de 50\%) são ligados à área de serviços. A maioria dos setores de atividade cujo coeficiente associado ao uso de computador é superior a 0,5 (correspondendo a um diferencial de rendimento de $65 \%$ ), está no ramo industrial. A mesma tendência é verificada em 2008. Esses resultados podem estar associados ao fato de que nos setores industriais, onde tecnologias mais modernas devem ser mais importantes, o diferencial de rendimentos por uso de internet é mais acentuado do que no setor de serviços. 
Na Figura 4, os coeficientes estimados são relacionados com a proporção de trabalhadores qualificados no setor de atividade. Nota-se também que os valores mais altos dos coeficientes estimados estão associados a setores em que a proporção de trabalhadores qualificados é menor, tanto em 2005 quanto em 2008.

\subsection{Tecnologia e distribuição dos rendimentos do trabalho}

Nesta seção, são apresentados os resultados de um exercício contrafactual em que são simulados os rendimentos dos trabalhadores que não utilizaram internet no trabalho ao impor a esses indivíduos a mesma estrutura de remuneração daqueles que fizeram uso de internet no trabalho. Essa análise é implementada seguindo a metodologia proposta por DiNardo et al. (1996).

Para isso, classificamos os trabalhadores em dois grupos, os que tiveram acesso a computadores no posto de trabalho $(h=1)$ e os que não tiveram $(h=$ $0)$. Seguindo DiNardo et al. (1996), a densidade dos rendimentos $(w)$ para cada grupo $h$ pode ser representada por:

$$
f_{h}(w)=\int_{z \in \Omega_{z}} d F\left(w, z / h_{w, z}=h_{i}\right),
$$

onde $z$ são características individuais e $\Omega_{z}$ o domínio de características individuais.

Note que podemos escrever:

$$
f_{h}(w)=\int_{z \in \Omega_{z}} f\left(w / z, h_{w}=h\right) d F\left(z / h_{z}=h\right) \equiv f\left(w ; h_{w}=h, h_{z}=h\right) .
$$

Dessa forma, a distribuição de rendimentos é representada condicionada nas características dos trabalhadores, e a distribuição dessas características é representada condicionada no grupo $h$. A distribuição de rendimentos para os trabalhadores que não utilizaram internet é dada por $f\left(w ; h_{w}=0, h_{z}=0\right)$. A distribuição de rendimentos contrafactual com as características dos trabalhadores que não usaram internet, mas as remunerações dos que utilizaram, é $f\left(w ; h_{w}=1, h_{z}=0\right)$.

Supondo que a estrutura de remuneração do grupo que não utilizou internet não dependa da distribuição de $\mathrm{z}$, a densidade $f\left(w ; h_{w}=1, h_{z}=0\right)$ pode ser representada por:

$$
\begin{aligned}
f_{h}\left(w, h_{w}=1, h_{z}=0\right) & =\int f\left(w / z, h_{w}=1\right) d F\left(z / h_{z}=0\right) \\
& =\int f\left(w / z, h_{w}=1\right) \psi_{z} d F\left(z / h_{z}=1\right),
\end{aligned}
$$

onde a função $\psi_{z}(z)$ faz um mapeamento da distribuição de características de $z$ para $h=0$ na distribuição de $h=1: \psi_{z}=\frac{d F\left(z / h_{z}=0\right)}{d F\left(z / h_{z}=1\right)}$. Essa função repondera a densidade para $h=1$ de tal forma que observações mais prováveis de aparecerem na distribuição de $h=0$ recebem um peso maior. Esses pesos podem ser estimados da seguinte forma: $\hat{\psi}_{z}=\frac{P\left(h_{z}=1 / z\right)}{P\left(h_{z}=0 / z\right)} \frac{P\left(h_{z}=0\right)}{P\left(h_{z}=1\right)}$.

As Figuras 4 e 4 apresentam as médias dos rendimentos em cada centésimo da distribuição observada dos trabalhadores que não utilizaram internet 
no trabalho, assim como os rendimentos contrafactuais caso os trabalhadores desse grupo fossem remunerados pelas suas características observadas da mesma forma que os trabalhadores que utilizaram internet. De acordo com os resultados, tanto para 2005 quanto para 2008, os rendimentos seriam maiores nessa distribuição contrafactual para todos os centésimos da distribuição. As Figuras 4 e 4 mostram as diferenças entre o log dos rendimentos médios nas duas distribuições para cada centésimo. As diferenças para 2005 são bastante acentuadas para os trabalhadores com menores rendimentos, diminuem e passam a aumentar em torno do $30^{\circ}$ centésimo da distribuição. Para 2008, as diferenças também são maiores nos primeiros e nos últimos centésimos da distribuição.

Os resultados desse exercício sugerem, portanto, que os maiores diferenciais nos rendimentos associados ao acesso a computadores seriam verificados para os trabalhadores nas caudas inferior e superior da distribuição de rendimentos. Esses resultados estão de acordo com a hipótese de polarização do mercado de trabalho, onde os ganhos em termos de rendimentos são superiores nos extremos, conforme Autor et al. (2006).

Novas distribuições contrafactuais que usam os rendimentos simulados para os trabalhadores que não utilizaram internet e os valores de fato observados para os indivíduos que utilizaram internet apresentam níveis de desigualdade bem menores. Em 2005, o índice de Theil para a distribuição de rendimentos do trabalho era igual a 0,593 . Impondo os retornos das características dos trabalhadores que utilizaram internet a todos os demais, o Theil diminui para 0,401 . Utilizando o Theil-L também é verificada uma queda acentuada da desigualdade (de 0,512 para 0,387). Essas reduções seriam proporcionadas por diminuições na desigualdade entre grupos (entre os trabalhadores que usaram internet e aqueles que não utilizaram internet no local de trabalho). Em 2008, verifica-se o mesmo padrão. O índice de Theil observado é 0,558 , enquanto na distribuição contrafactual é igual a 0,443. Para o Theil-L a redução seria de 0,470 para 0,401 .

\section{Considerações finais}

Já é consenso na literatura que os rendimentos do trabalho no Brasil são distribuídos de forma extremamente desigual. Analisamos neste artigo em que medida o acesso a novas tecnologias no ambiente de trabalho pode estar associado às diferenças observadas na estrutura de remunerações.

Os resultados, estimados usando dados do suplemento sobre inovações tecnológicas das PNADs de 2005 e 2008, mostram que trabalhadores que utilizaram internet no local de trabalho nos 3 meses anteriores à pesquisa recebem rendimentos muito superiores aos demais trabalhadores que não usaram essa tecnologia durante o mesmo período. Esses mesmos resultados são observados para diversas ocupações e setores de atividade separadamente. Evidências obtidas a partir de simulações contrafactuais mostram que se trabalhadores sem acesso a internet no local de trabalho tivessem as suas características remuneradas da mesma forma que aqueles com acesso a essa tecnologia, a desigualdade seria substancialmente reduzida.

Os diferenciais de rendimentos associados ao uso de internet no trabalho são bastante acentuados. Deve-se considerar, porém, que os resultados aqui apresentados podem ser devidos tanto a um impacto direto da tecnologia so- 
bre a produtividade, quanto ao fato do uso de internet estar correlacionado com características não observadas do posto de trabalho que influenciam a produtividade do trabalhador, ou ainda pelo fato de trabalhadores com melhores características não observadas serem normalmente alocados nos melhores postos de trabalho.

A identificação da importância de cada um desses fatores tem implicações para a definição das políticas públicas mais adequadas para aumentar a produtividade do trabalho e reduzir a desigualdade de rendimentos. Se o acesso a computadores tem um efeito direto sobre a produtividade, podem ser adotadas políticas que incentivem a expansão de novas tecnologias. Isso pode ser feito, por exemplo, através de programas de microcrédito para pequenas empresas. Medidas desse tipo podem ser importantes mesmo que o acesso a internet esteja apenas captando os efeitos de melhores condições no posto de trabalho, já que essas variáveis devem ser correlacionadas. Se, no entanto, o que importa é a qualificação do trabalhador, e apenas aqueles com melhores atributos são capazes de operar novas tecnologias, políticas de investimento em capital humano são fundamentais, mesmo que parte do diferencial de rendimentos se deva a características inatas. Deve-se ressaltar que políticas de incentivo a modernização tecnológica das firmas e de qualificação dos trabalhadores podem ser mais eficientes se adotadas conjuntamente, pela interação que deve existir entre essas variáveis.

Não é possível na nossa análise, com os dados disponíveis, identificar a importância relativa de cada um desses fatores, e portanto, indicar a política pública mais apropriada. O que o artigo mostra, porém, é que os diferenciais de rendimentos associados a disparidades no acesso a novas tecnologias são muito acentuados. Além disso, as implicações desses resultados para a distribuição de rendimentos como um todo também se mostram bastante importantes. 

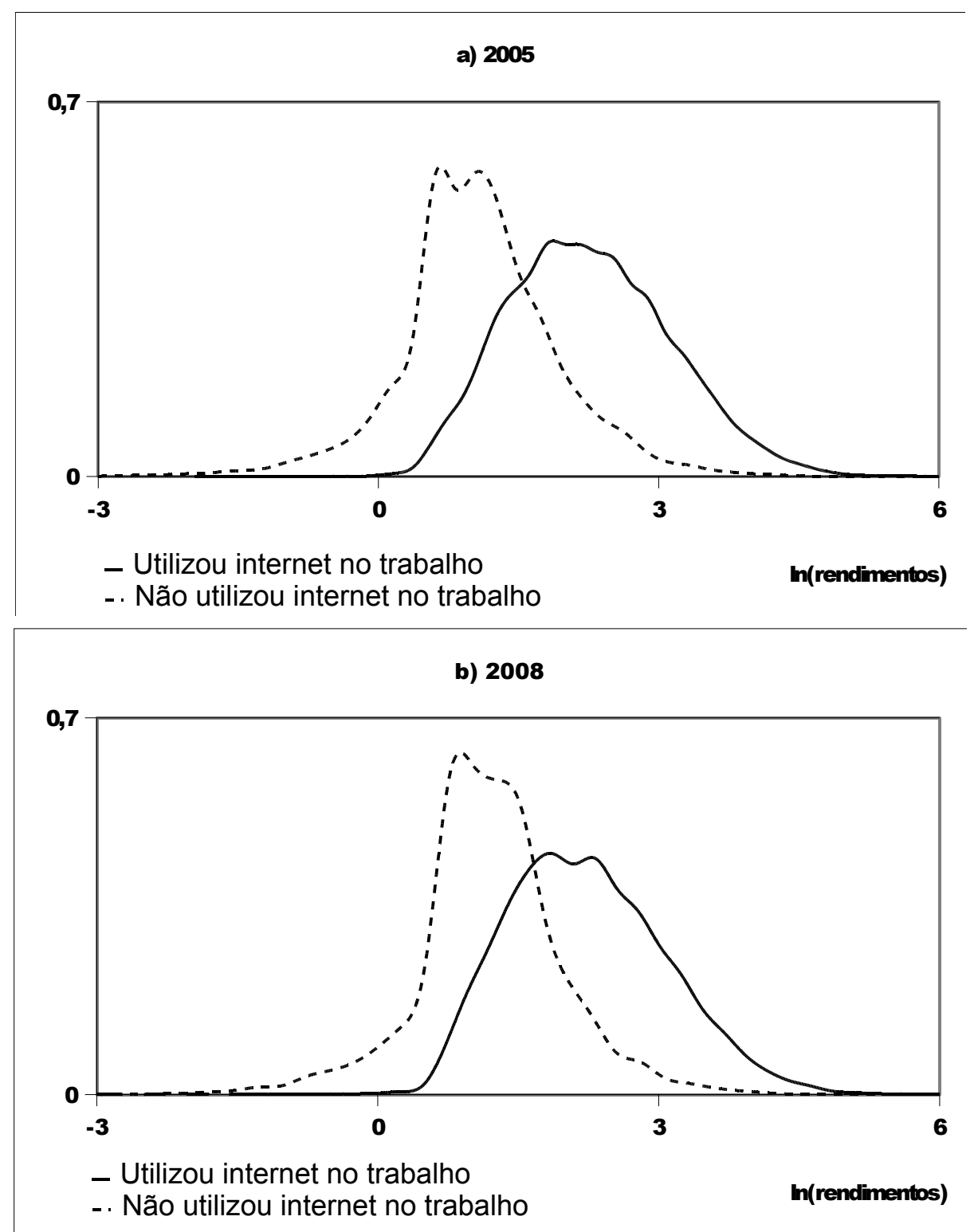

Fonte: PNAD 2005 e 2008

Figura 1: Distribuição dos rendimentos por hora segundo o uso 
Tabela 1: Características dos trabalhadores segundo o uso de internet no trabalho

\begin{tabular}{|c|c|c|c|c|}
\hline & \multicolumn{2}{|c|}{2005} & \multicolumn{2}{|c|}{2008} \\
\hline & $\begin{array}{l}\text { Não usou } \\
\text { internet }\end{array}$ & $\begin{array}{c}\text { Usou } \\
\text { internet }\end{array}$ & $\begin{array}{l}\text { Não usou } \\
\text { internet }\end{array}$ & $\begin{array}{c}\text { Usou } \\
\text { internet }\end{array}$ \\
\hline Rendimento médio mensal (R\$) & 746,94 & 2532,86 & 813,58 & 2434,36 \\
\hline Rendimento médio por hora ( $\mathrm{R} \$)$ & 4,17 & 14,35 & 4,61 & 14,01 \\
\hline Anos de escolaridade & 6,55 & 12,89 & 6,99 & 12,82 \\
\hline Idade média & 40,84 & 38,39 & 41,29 & 38,66 \\
\hline Faixas etárias (\%) 25 a 39 anos & 48,86 & 58,23 & 46,70 & 57,41 \\
\hline 40 a 54 anos & 40,07 & 36,45 & 41,32 & 36,13 \\
\hline 55 a 65 anos & 11,06 & 5,32 & 11,99 & 6,46 \\
\hline Homens (\%) & 61,55 & 57,40 & 60,67 & 55,31 \\
\hline Negros $(\%)$ & 50,36 & 25,98 & 53,28 & 29,48 \\
\hline Posição na ocupação (\%) Com carteira & 35,20 & 50,58 & 38,52 & 49,80 \\
\hline Sem carteira & 23,21 & 10,59 & 22,59 & 10,41 \\
\hline Conta-própria & 29,74 & 9,00 & 27,41 & 9,00 \\
\hline Empregador & 4,83 & 10,70 & 4,56 & 10,82 \\
\hline Militar & 0,08 & 0,79 & 0,08 & 0,61 \\
\hline Funcionário público & 6,95 & 18,34 & 6,84 & 19,36 \\
\hline Setor de atividade (\%) Agricultura & 15,31 & 0,49 & 13,81 & 0,62 \\
\hline Indústria & 15,87 & 15,58 & 16,36 & 14,83 \\
\hline Construção & 8,73 & 2,41 & 10,08 & 2,53 \\
\hline Comércio & 17,46 & 16,61 & 16,38 & 17,34 \\
\hline Serviços & 32,62 & 28,93 & 33,83 & 30,66 \\
\hline Administração Pública & 4,77 & 14,62 & 4,34 & 13,35 \\
\hline Outros & 5,25 & 21,37 & 5,21 & 20,67 \\
\hline Usou internet em casa (\%) & 5,61 & 50,07 & 11,84 & 65,64 \\
\hline Observações & 99.455 & 19.231 & 98.177 & 24.859 \\
\hline Participação no total (\%) & 83,85 & 16,15 & 79,80 & 20,20 \\
\hline
\end{tabular}

Fonte: Elaboração própria a partir dos Microdados da PNAD 2005, Suplemento. 
Tabela 2: Regressões para a relação entre uso de internet e rendimentos do trabalho - 2005

\begin{tabular}{|c|c|c|c|c|c|}
\hline \multicolumn{6}{|c|}{ Variável dependente: ln (rendimento do trabalho por hora) } \\
\hline & (1) & (2) & (3) & (4) & (5) \\
\hline Usou internet no trabalho & $\begin{array}{l}1,2083 \\
(159,58)\end{array}$ & $\begin{array}{c}0,4931 \\
(70,17)\end{array}$ & $\begin{array}{c}0,3801 \\
(52,05)\end{array}$ & $\begin{array}{c}0,4645 \\
(64,79)\end{array}$ & $\begin{array}{c}0,3525 \\
(48,12)\end{array}$ \\
\hline Anos de escolaridade & & $\begin{array}{c}0,088 \\
(142,17)\end{array}$ & $\begin{array}{l}0,063 \\
(90,43)\end{array}$ & $\begin{array}{l}0,0758 \\
(114,69)\end{array}$ & $\begin{array}{c}0,0603 \\
(85,76)\end{array}$ \\
\hline Idade & & $\begin{array}{c}0,0488 \\
(25,47)\end{array}$ & $\begin{array}{c}0,0439 \\
(23,78)\end{array}$ & $\begin{array}{c}0,0447 \\
(23,80)\end{array}$ & $\begin{array}{c}0,0424 \\
(23,12)\end{array}$ \\
\hline Idade ao quadrado & & $\begin{array}{c}-0,0004 \\
(18,52)\end{array}$ & $\begin{array}{c}-0,0004 \\
(17,22)\end{array}$ & $\begin{array}{c}-0,0004 \\
(17,03)\end{array}$ & $\begin{array}{c}-0,0004 \\
(16,78)\end{array}$ \\
\hline Homem & & $\begin{array}{c}0,2893 \\
(64,01)\end{array}$ & $\begin{array}{c}0,2483 \\
(48,03)\end{array}$ & $\begin{array}{l}0,275 \\
(49,84)\end{array}$ & $\begin{array}{r}0,2417 \\
(43,29)\end{array}$ \\
\hline Negro & & $\begin{array}{c}-0,1255 \\
(27,29)\end{array}$ & $\begin{array}{c}-0,1117 \\
(25,36)\end{array}$ & $\begin{array}{c}-0,1255 \\
(27,89)\end{array}$ & $\begin{array}{c}-0,1108 \\
(25,32)\end{array}$ \\
\hline Nordeste & & $\begin{array}{c}-0,3238 \\
(44,34)\end{array}$ & $\begin{array}{r}-0,3142 \\
(44,54)\end{array}$ & $\begin{array}{c}-0,3095 \\
(42,98)\end{array}$ & $\begin{array}{r}-0,3169 \\
(44,88)\end{array}$ \\
\hline Sudeste & & $\begin{array}{c}0,0604 \\
(8,73)\end{array}$ & $\begin{array}{c}0,0478 \\
(7,11)\end{array}$ & $\begin{array}{c}0,0527 \\
(7,66)\end{array}$ & $\begin{array}{c}0,0457 \\
(6,78)\end{array}$ \\
\hline Sul & & $\begin{array}{c}0,0242 \\
(3,02)\end{array}$ & $\begin{array}{c}0,0363 \\
(4,65)\end{array}$ & $\begin{array}{c}0,0353 \\
(4,42)\end{array}$ & $\begin{array}{c}0,0395 \\
(5,05)\end{array}$ \\
\hline Centro-Oeste & & $\begin{array}{l}0,081 \\
(10,00)\end{array}$ & $\begin{array}{c}0,0828 \\
(10,50)\end{array}$ & $\begin{array}{c}0,0941 \\
(11,65)\end{array}$ & $\begin{array}{c}0,0843 \\
(10,69)\end{array}$ \\
\hline Sem carteira & & $\begin{array}{c}-0,2047 \\
(38,14)\end{array}$ & $\begin{array}{c}-0,2111 \\
(40,42)\end{array}$ & $\begin{array}{r}-0,1587 \\
(28,64)\end{array}$ & $\begin{array}{c}-0,2044 \\
(38,00)\end{array}$ \\
\hline Conta-própria & & $\begin{array}{c}-0,1845 \\
(30,32)\end{array}$ & $\begin{array}{c}-0,1458 \\
(21,95)\end{array}$ & $\begin{array}{c}-0,1087 \\
(16,98)\end{array}$ & $\begin{array}{c}-0,1294 \\
(18,63)\end{array}$ \\
\hline Empregador & & $\begin{array}{c}0,4855 \\
(41,00)\end{array}$ & $\begin{array}{c}0,3248 \\
(22,48)\end{array}$ & $\begin{array}{c}0,5736 \\
(47,92)\end{array}$ & $\begin{array}{c}0,3684 \\
(25,43)\end{array}$ \\
\hline Militar & & $\begin{array}{c}0,4789 \\
(12,94)\end{array}$ & $\begin{array}{c}0,4622 \\
(6,08)\end{array}$ & $\begin{array}{c}0,3705 \\
(9,82)\end{array}$ & $\begin{array}{c}0,4096 \\
(5,53)\end{array}$ \\
\hline Funcionário público & & $\begin{array}{c}0,2483 \\
(34,08)\end{array}$ & $\begin{array}{c}0,1592 \\
(20,55)\end{array}$ & $\begin{array}{c}0,1294 \\
(13,84)\end{array}$ & $\begin{array}{c}0,1050 \\
(11,71)\end{array}$ \\
\hline Constante & $\begin{array}{c}1,053 \\
(359,17)\end{array}$ & $\begin{array}{c}-0,7784 \\
(19,51)\end{array}$ & $\begin{array}{c}-0,2569 \\
(2,50)\end{array}$ & $\begin{array}{c}-0,8921 \\
(22,50)\end{array}$ & $\begin{array}{c}-0,3142 \\
(3,02)\end{array}$ \\
\hline $\begin{array}{l}\text { Dummies para ocupação } \\
\text { (2-dígitos) }\end{array}$ & Não & Não & $\operatorname{Sim}$ & Não & Sim \\
\hline $\begin{array}{l}\text { Dummies para setor de } \\
\text { atividade ( } 2 \text {-dígitos) }\end{array}$ & Não & Não & Não & Sim & Sim \\
\hline Observações & 118.686 & 118.676 & 118.659 & 118.676 & 118.659 \\
\hline $\mathrm{R} 2$ & 0,22 & 0,52 & 0,56 & 0,54 & 0,56 \\
\hline
\end{tabular}

Fonte: Elaboração própria a partir dos Microdados da PNAD 2005, Suplemento. Notas: Entre parênteses, estatística t robusta. 
Tabela 3: Regressões para a relação entre uso de internet e rendimentos do trabalho - 2008

\begin{tabular}{|c|c|c|c|c|c|}
\hline \multicolumn{6}{|c|}{ Variável dependente: ln (rendimento do trabalho por hora) } \\
\hline & (1) & (2) & (3) & (4) & (5) \\
\hline Usou internet no trabalho & $\begin{array}{l}1,0436 \\
(159,22)\end{array}$ & $\begin{array}{c}0,4442 \\
(71,86)\end{array}$ & $\begin{array}{c}0,3046 \\
(46,92)\end{array}$ & $\begin{array}{c}0,4128 \\
(65,96)\end{array}$ & $\begin{array}{c}0,2824 \\
(43,60)\end{array}$ \\
\hline Anos de escolaridade & & $\begin{array}{l}0,0791 \\
(130,18)\end{array}$ & $\begin{array}{c}0,0556 \\
(83,41)\end{array}$ & $\begin{array}{l}0,0688 \\
(106,99)\end{array}$ & $\begin{array}{c}0,0528 \\
(79,01)\end{array}$ \\
\hline Idade & & $\begin{array}{c}0,0414 \\
(22,44)\end{array}$ & $\begin{array}{c}0,0378 \\
(21,34)\end{array}$ & $\begin{array}{c}0,0379 \\
(20,93)\end{array}$ & $\begin{array}{c}0,0362 \\
(20,58)\end{array}$ \\
\hline Idade ao quadrado & & $\begin{array}{c}-0,0004 \\
(15,97)\end{array}$ & $\begin{array}{c}-0,0003 \\
(15,33)\end{array}$ & $\begin{array}{c}-0,0003 \\
(14,66)\end{array}$ & $\begin{array}{c}-0,0003 \\
(14,76)\end{array}$ \\
\hline Homem & & $\begin{array}{c}0,2968 \\
(69,07)\end{array}$ & $\begin{array}{c}0,2502 \\
(50,85)\end{array}$ & $\begin{array}{c}0,2792 \\
(52,96)\end{array}$ & $\begin{array}{c}0,2443 \\
(46,07)\end{array}$ \\
\hline Negro & & $\begin{array}{c}-0,1213 \\
(27,55)\end{array}$ & $\begin{array}{c}-0,1076 \\
(25,56)\end{array}$ & $\begin{array}{c}-0,1228 \\
(28,41)\end{array}$ & $\begin{array}{c}-0,1065 \\
(25,49)\end{array}$ \\
\hline Nordeste & & $\begin{array}{r}-0,2621 \\
(35,60)\end{array}$ & $\begin{array}{c}-0,2514 \\
(35,27)\end{array}$ & $\begin{array}{c}-0,2493 \\
(34,42)\end{array}$ & $\begin{array}{c}-0,2522 \\
(35,70)\end{array}$ \\
\hline Sudeste & & $\begin{array}{c}0,0775 \\
(11,08)\end{array}$ & $\begin{array}{c}0,07 \\
(10,29)\end{array}$ & $\begin{array}{c}0,0708 \\
(10,19)\end{array}$ & $\begin{array}{c}0,0671 \\
(9,92)\end{array}$ \\
\hline Sul & & $\begin{array}{c}0,0429 \\
(5,29)\end{array}$ & $\begin{array}{c}0,0583 \\
(7,36)\end{array}$ & $\begin{array}{c}0,0519 \\
(6,43)\end{array}$ & $\begin{array}{c}0,061 \\
(7,74)\end{array}$ \\
\hline Centro-Oeste & & $\begin{array}{c}0,1153 \\
(13,86)\end{array}$ & $\begin{array}{c}0,1196 \\
(14,78)\end{array}$ & $\begin{array}{c}0,1252 \\
(15,14)\end{array}$ & $\begin{array}{c}0,1206 \\
(15,00)\end{array}$ \\
\hline Sem carteira & & $\begin{array}{c}-0,1833 \\
(35,17)\end{array}$ & $\begin{array}{c}-0,1878 \\
(37,35)\end{array}$ & $\begin{array}{r}-0,1477 \\
(27,56)\end{array}$ & $\begin{array}{c}-0,1849 \\
(35,74)\end{array}$ \\
\hline Conta-própria & & $\begin{array}{c}-0,1393 \\
(23,14)\end{array}$ & $\begin{array}{c}-0,0988 \\
(15,30)\end{array}$ & $\begin{array}{c}-0,0684 \\
(10,88)\end{array}$ & $\begin{array}{r}-0,0885 \\
(13,18)\end{array}$ \\
\hline Empregador & & $\begin{array}{c}0,5124 \\
(44,47)\end{array}$ & $\begin{array}{c}0,3378 \\
(24,69)\end{array}$ & $\begin{array}{c}0,5884 \\
(50,68)\end{array}$ & $\begin{array}{l}0,373 \\
(27,20)\end{array}$ \\
\hline Militar & & $\begin{array}{c}0,5705 \\
(14,63)\end{array}$ & $\begin{array}{c}0,4116 \\
(5,76)\end{array}$ & $\begin{array}{c}0,4487 \\
(11,16)\end{array}$ & $\begin{array}{c}0,3527 \\
(4,92)\end{array}$ \\
\hline Funcionário público & & $\begin{array}{c}0,2842 \\
(39,88)\end{array}$ & $\begin{array}{c}0,1971 \\
(26,25)\end{array}$ & $\begin{array}{c}0,1638 \\
(18,04)\end{array}$ & $\begin{array}{c}0,1322 \\
(15,26)\end{array}$ \\
\hline Constante & $\begin{array}{l}1,1926 \\
(431,83)\end{array}$ & $\begin{array}{c}-0,4982 \\
(12,90)\end{array}$ & $\begin{array}{c}0,3543 \\
(4,14)\end{array}$ & $\begin{array}{c}-0,6013 \\
(15,51)\end{array}$ & $\begin{array}{c}0,2826 \\
(3,21)\end{array}$ \\
\hline $\begin{array}{l}\text { Dummies para ocupação } \\
\text { (2-dígitos) }\end{array}$ & Não & Não & Sim & Não & Sim \\
\hline $\begin{array}{l}\text { Dummies para setor de } \\
\text { atividade ( } 2 \text {-dígitos) }\end{array}$ & Não & Não & Não & Sim & Sim \\
\hline Observações & 123.036 & 123.036 & 123.025 & 123.036 & 123.025 \\
\hline $\mathrm{R} 2$ & 0,21 & 0,48 & 0,53 & 0,5 & 0,54 \\
\hline
\end{tabular}

Fonte: Elaboração própria a partir dos Microdados da PNAD 2008, Suplemento. Notas: Entre parênteses, estatística t robusta. 


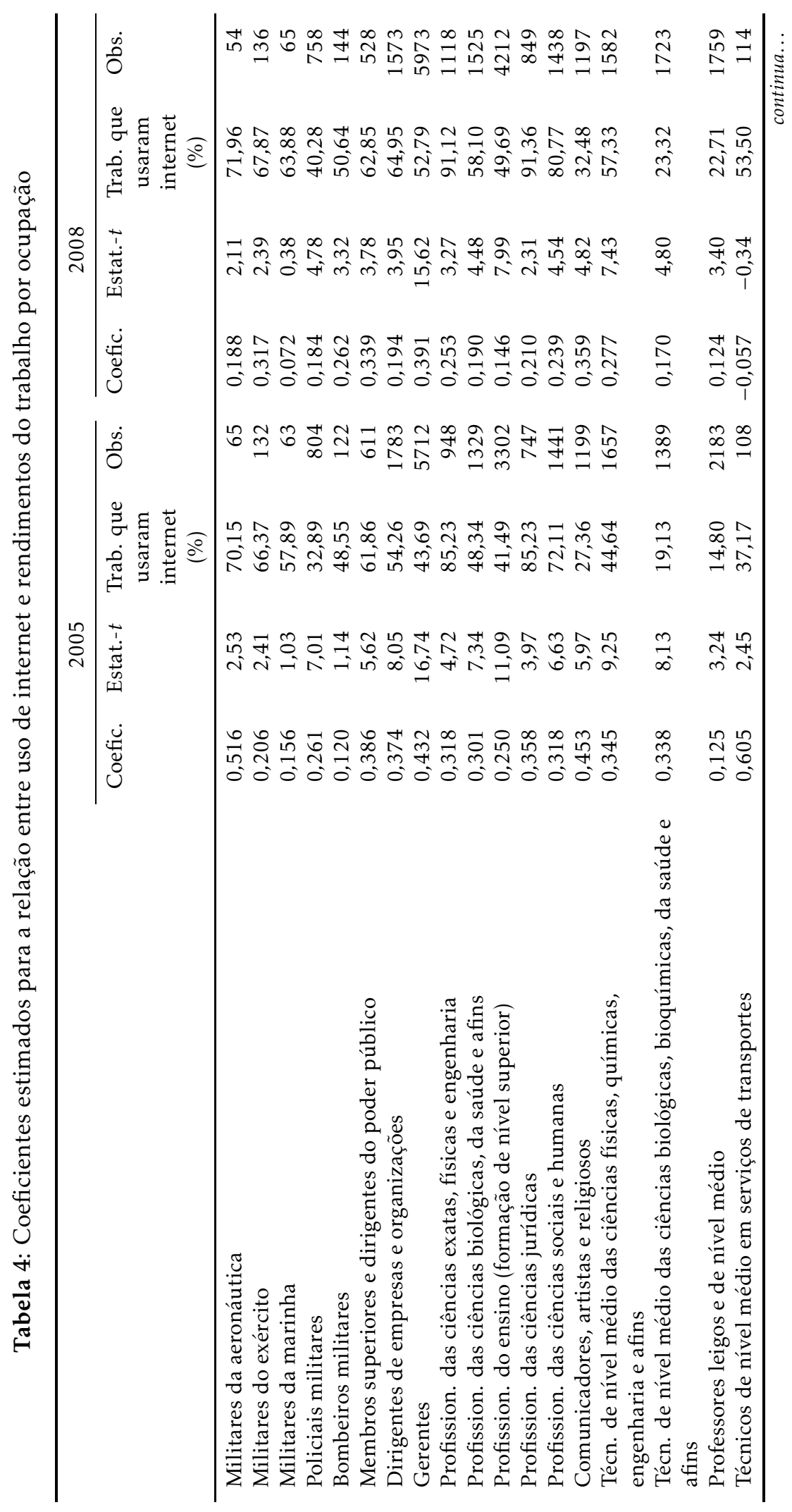




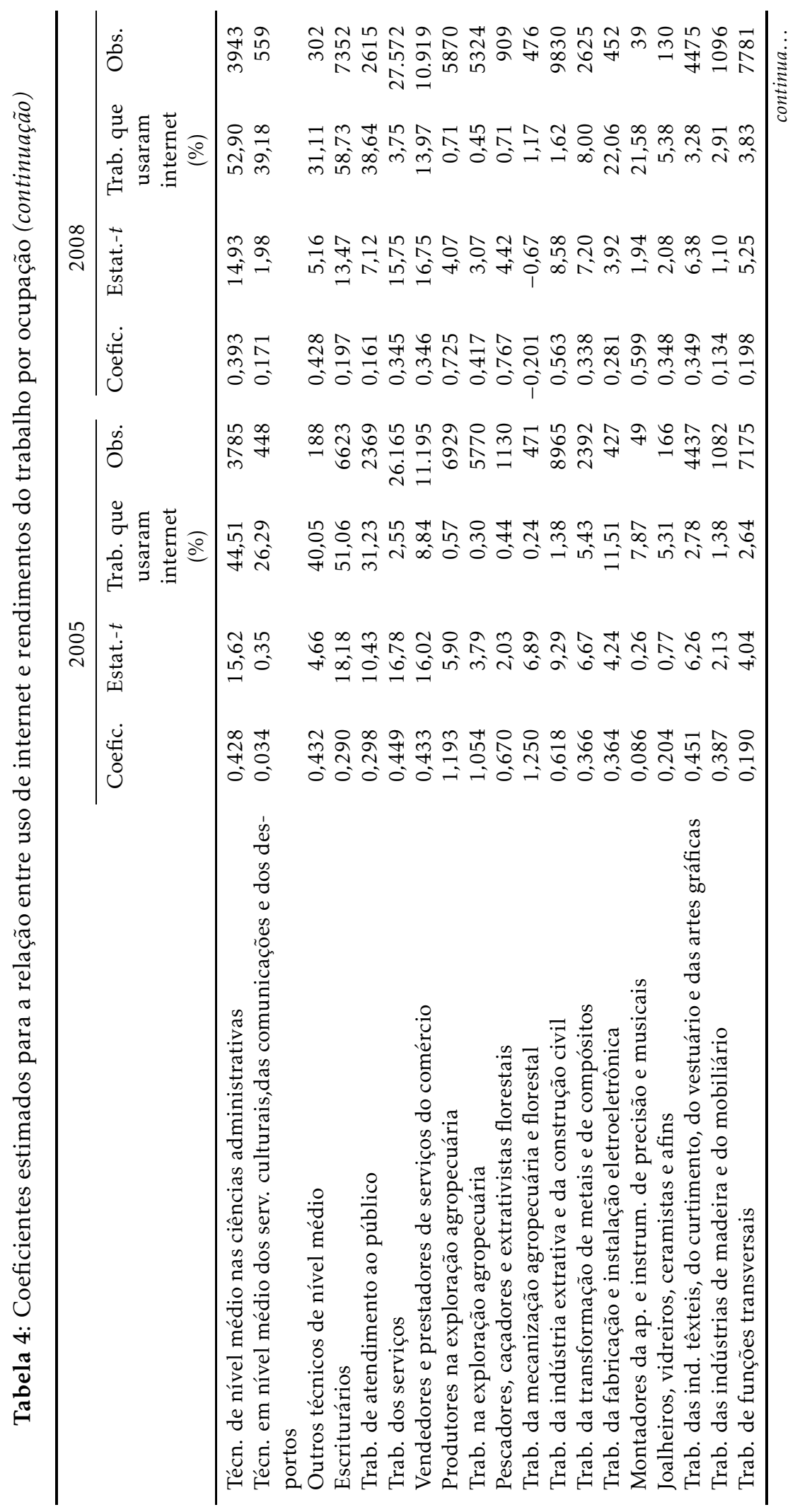




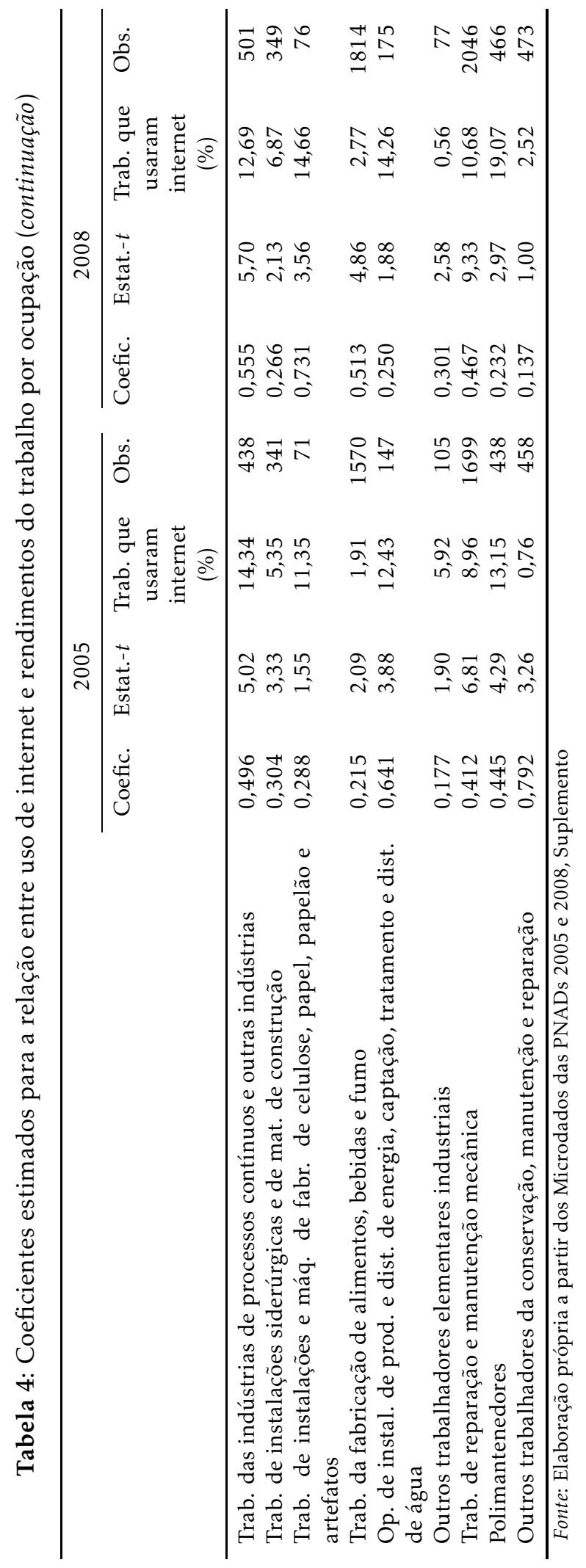




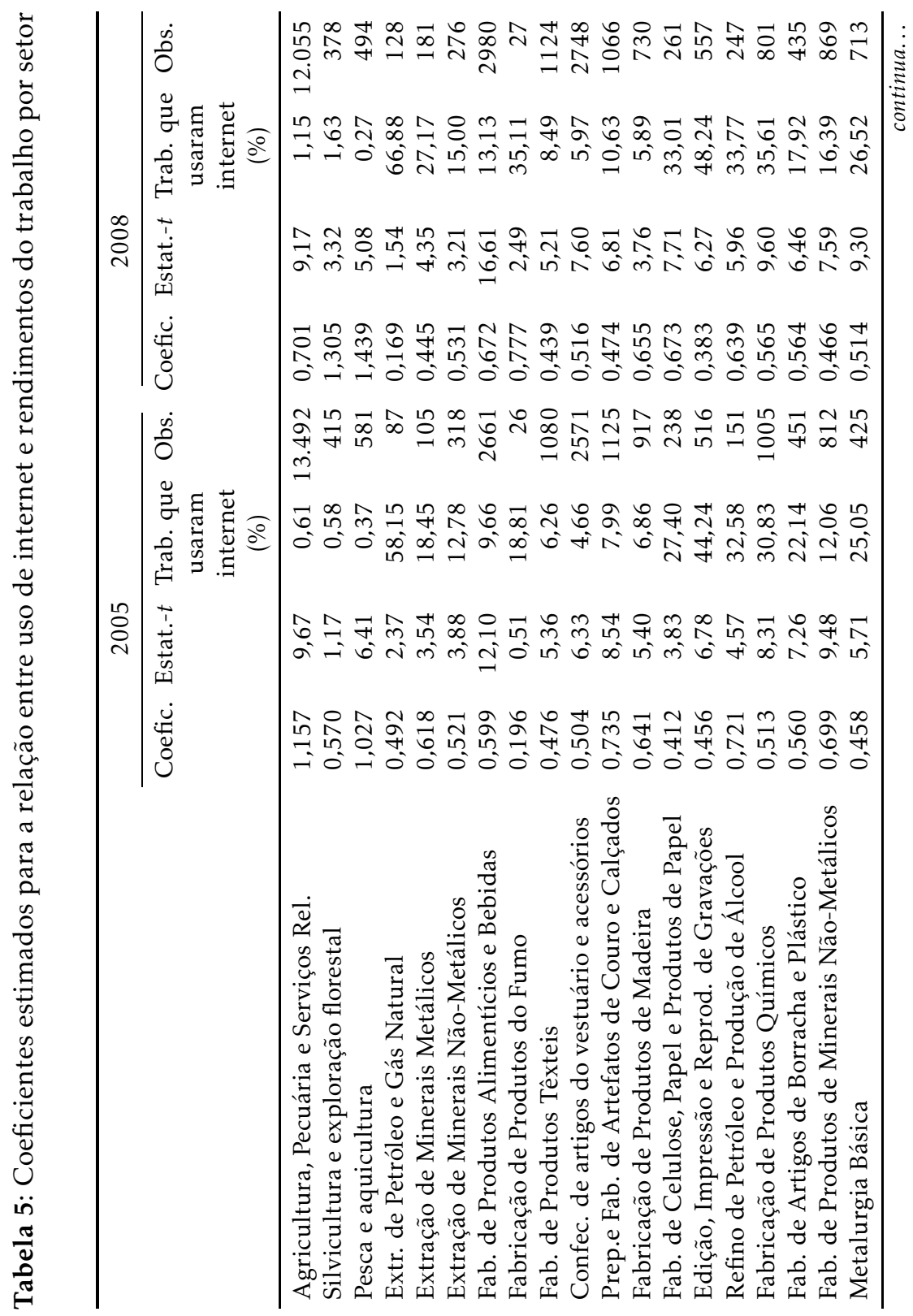




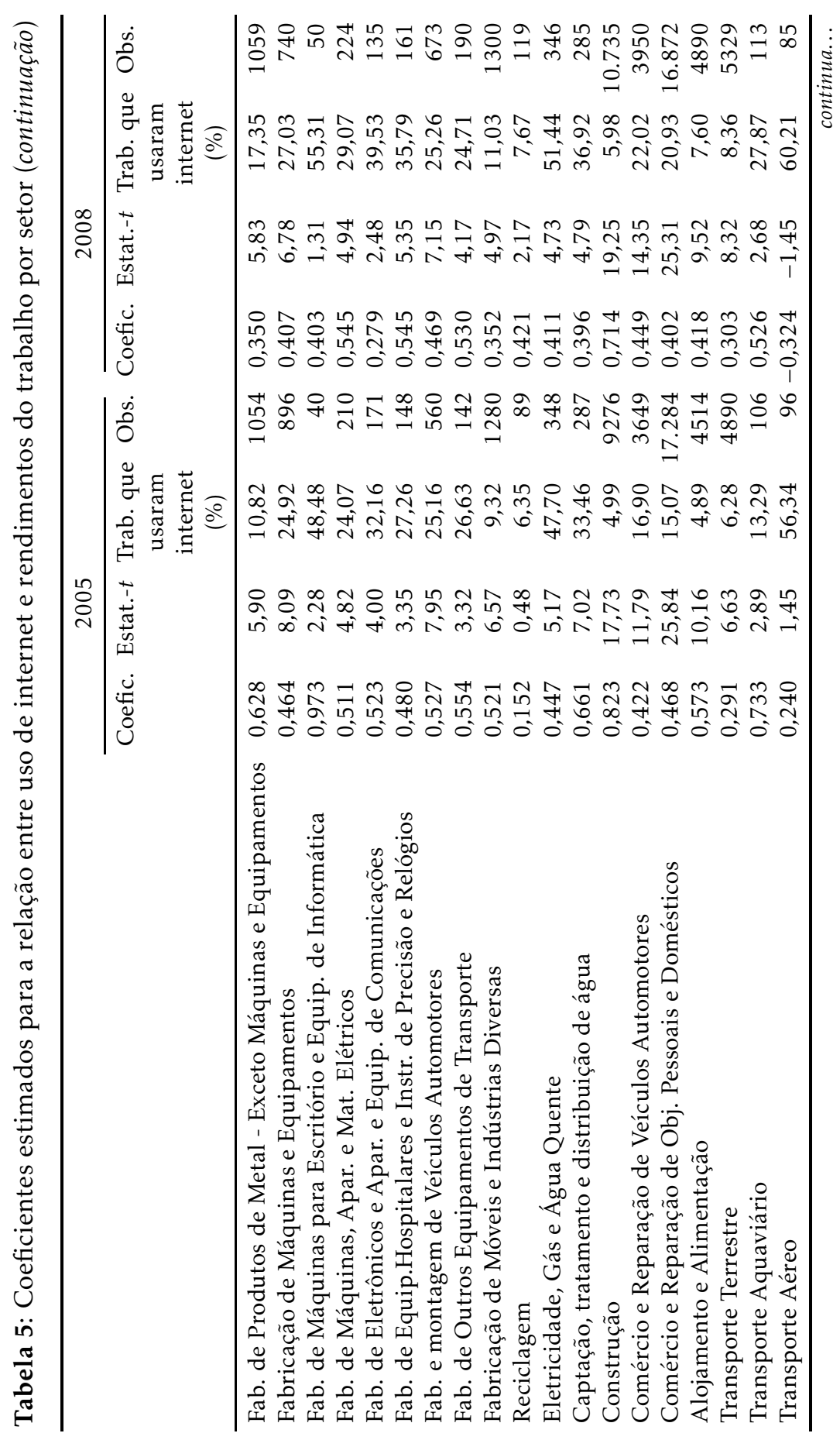




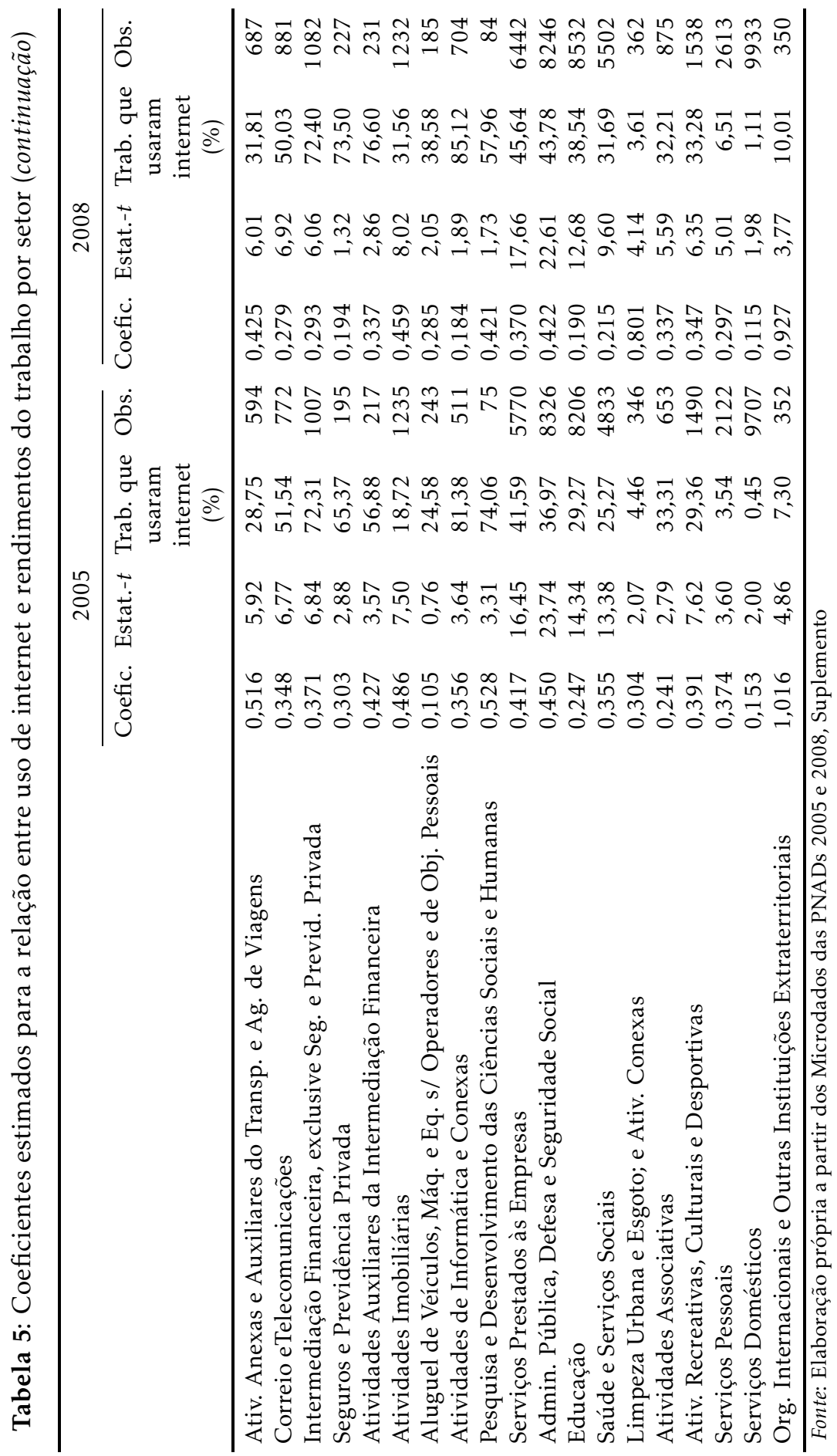



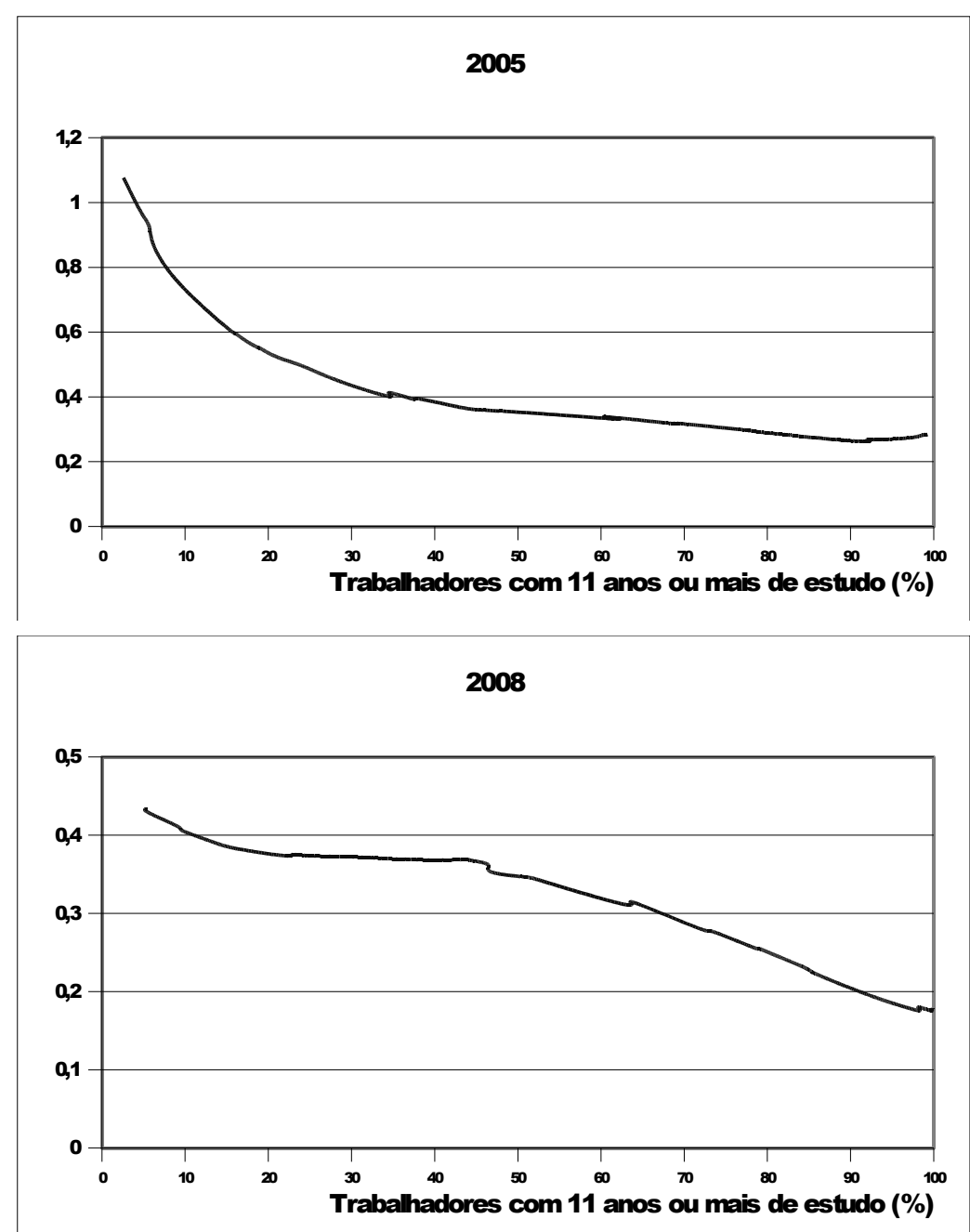

Nota: Resultados baseados nos coeficientes estimados reportados na Tabela 4 .

Figura 2: Relação entre coeficientes estimados para o uso de internet $\mathrm{e}$ proporção de trabalhadores qualificados por ocupação - LOWESS 

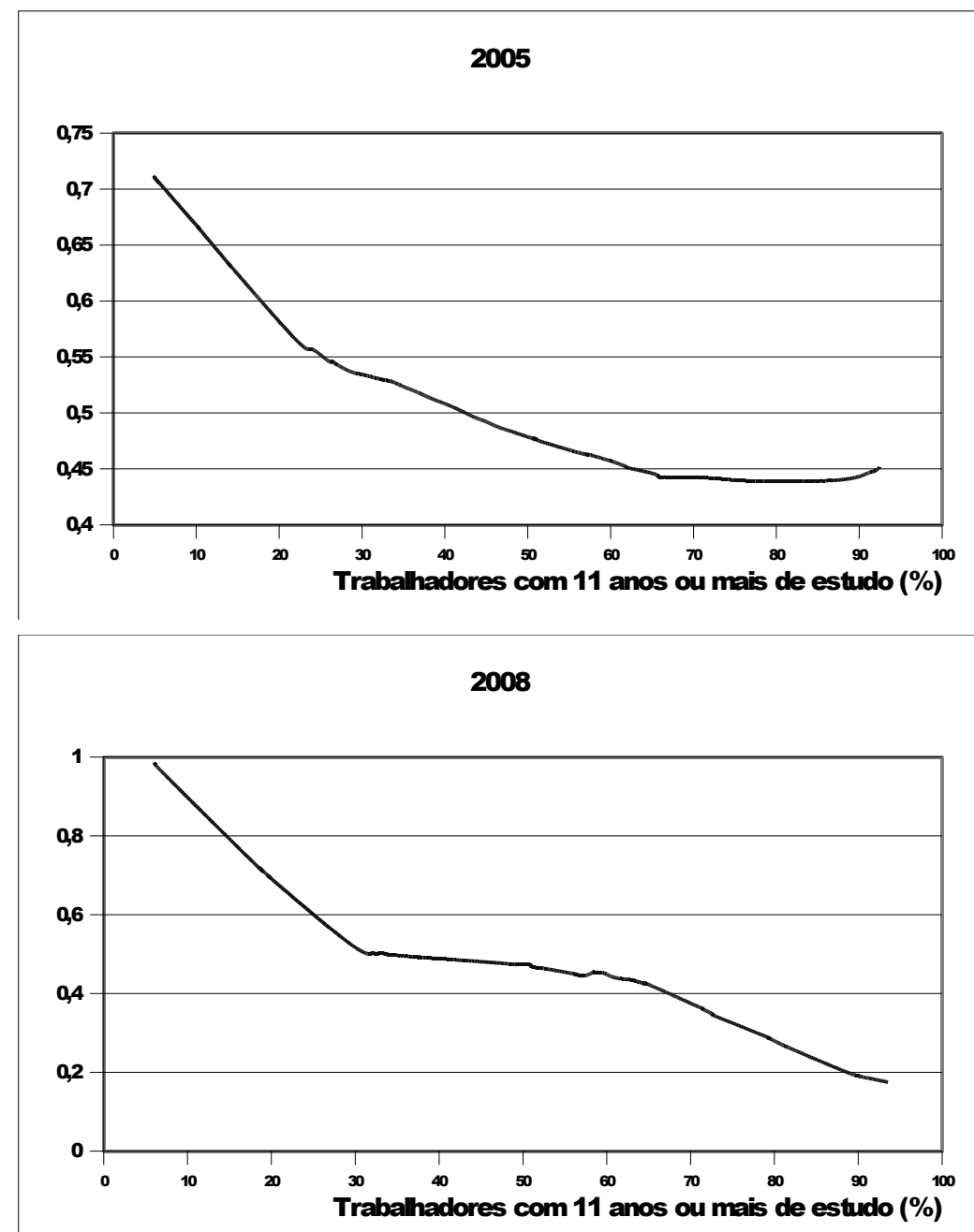

Nota: Resultados baseados nos coeficientes estimados reportados na Tabela 5.

Figura 3: Relação entre coeficientes estimados para o uso de internet $\mathrm{e}$ proporção de trabalhadores qualificados por setor - LOWESS 
(a): Rendimentos observados e contrafactuais para trabalhadores que não utilizaram internet no trabalho - por centésimo da distribuição de rendimentos 2005

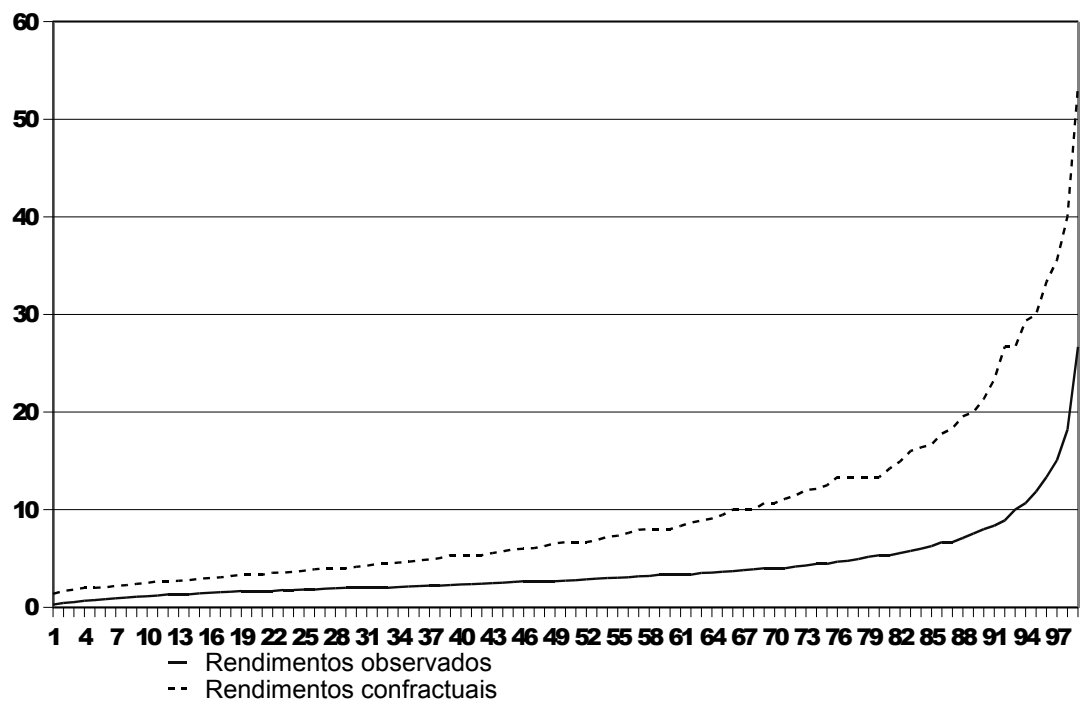

(b): Diferença entre rendimentos contrafactuais e observados para trabalhadores que não utilizaram internet no trabalho - por centésimo da distribuição de rendimentos - 2005

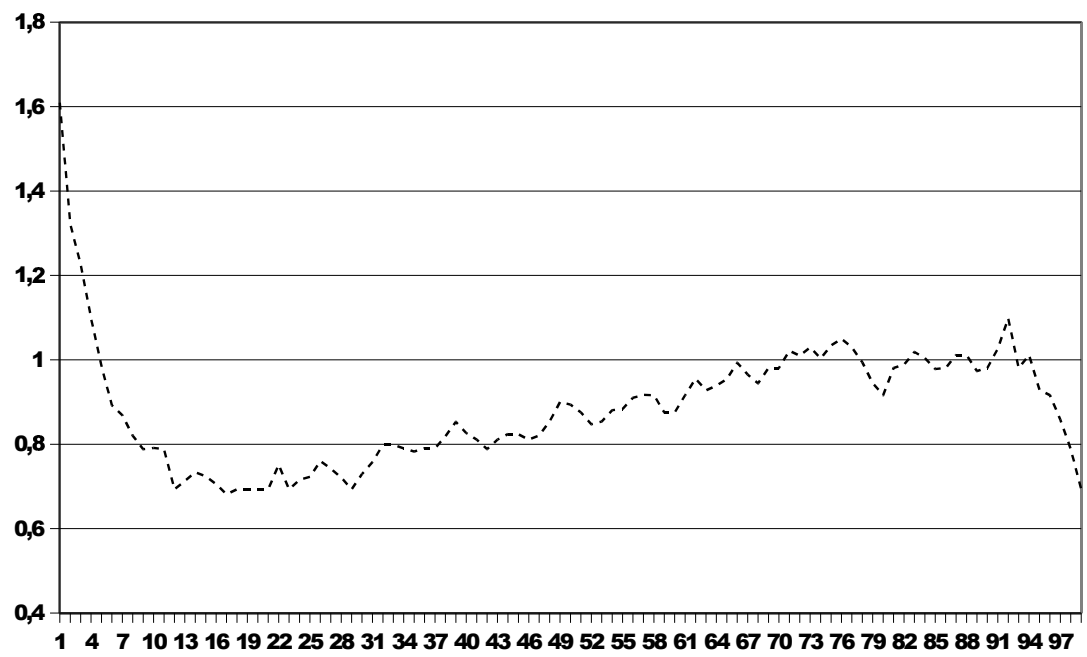

Figura 4: Rendimentos observados e contrafactuais (2005) 
(a): Rendimentos observados e contrafactuais para trabalhadores que não utilizaram internet no trabalho - por centésimo da distribuição de rendimentos 2008

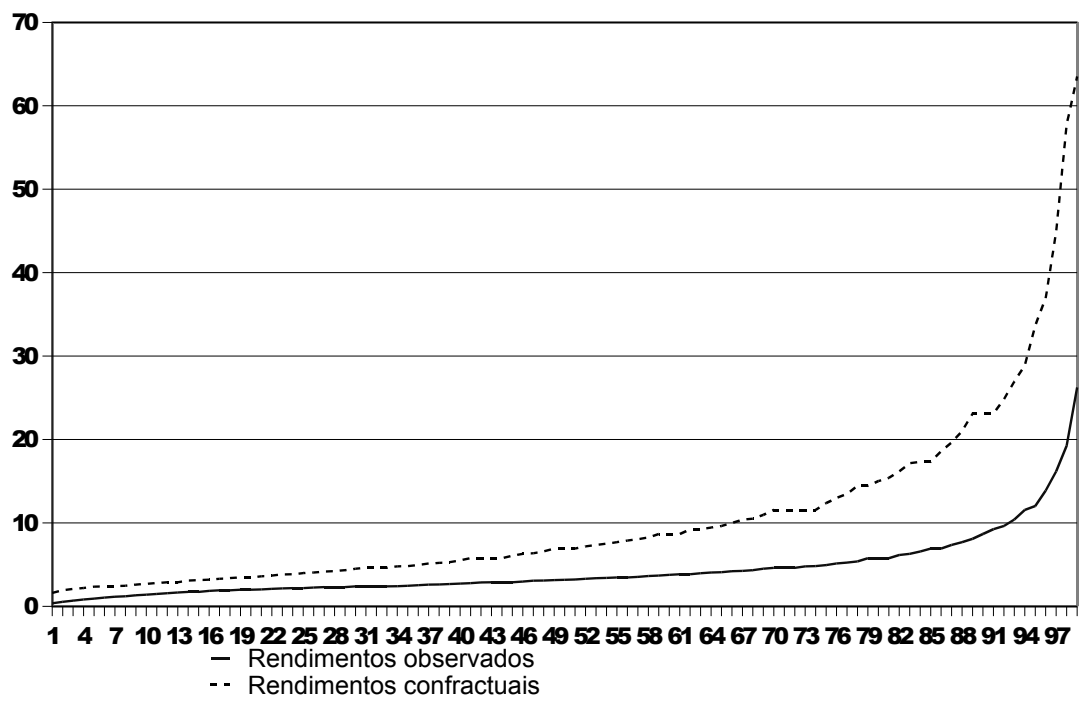

(b): Diferença entre rendimentos contrafactuais e observados para trabalhadores que não utilizaram internet no trabalho - por centésimo da distribuição de rendimentos - 2008

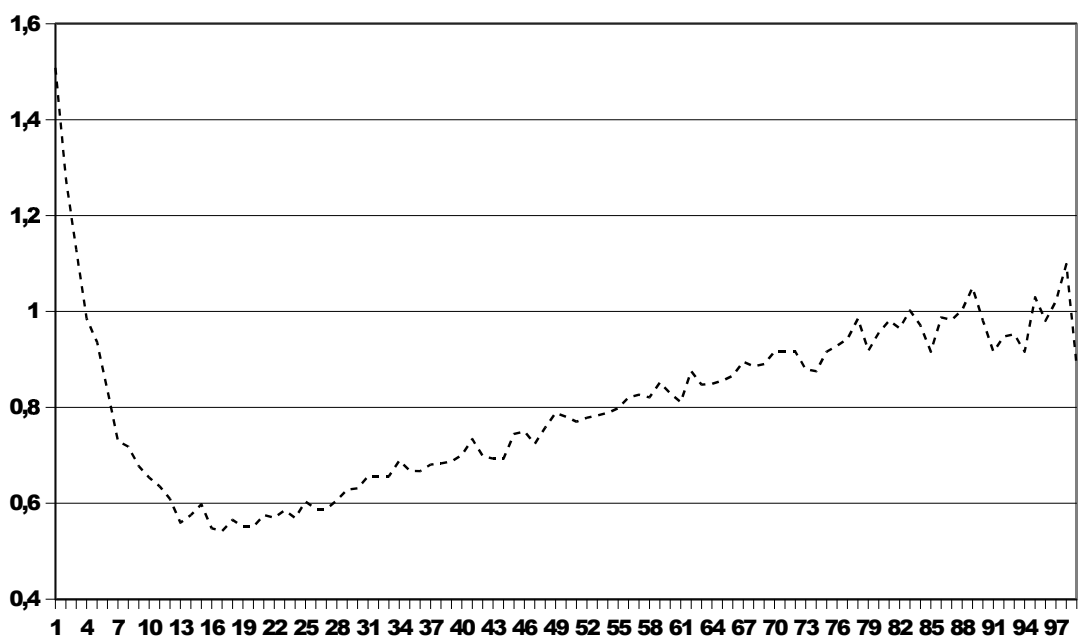

Figura 5: Rendimentos observados e contrafactuais (2008) 


\section{Referências Bibliográficas}

Autor, D. e. K. L. (1999), Changes in the Wage Structure and Earnings Inequality, in O. A. e. D. Card, ed., 'Handbook of Labor Economics', Vol. 3, Elsevier.

Autor, D. H., Katz, L. F. \& Kearney, M. S. (2006), 'The Polarization of US Labor Market', American Economic Review 96(2), 189-94.

Autor, D. H., Katz, L. F. \& Krueger, A. B. (1998), 'Computing Inequality: Have Computers Changed the Labor Market?', The Quartely Journal of Economics 113(4), 1169-1213.

Bell, B. (1996), 'Skill-biased technological change and wages: evidence for a longitudinal data set', Mimeo.

Bound, J. e. J. G. (1992), 'Changes in the Structure of Wages in the 1980s: an Evaluation of Alternative Explanations', American Economic Review 82(3), 371-392.

DiNardo, J. E. \& Pischke, J.-S. (1997), 'The return to computer use revisited: have pencils changed the wage structure too?', The Quartely Journal of Economics 112(1), 291-303.

DiNardo, J., Fortin, N. M. \& Lemieux, T. (1996), 'Labor Market Institutions and the Distribution of Wages, 1973-1992: A Semiparametric Approach', Econometrica 64(5), 1001-1014.

Entorf, H. \& Kramarz, F. (1997), 'Does unmeasured ability explain the higher wages of new technology workers?', European Economic Review 41(8), 14891510 .

Krueger, A. B. (1993), 'How computers have changed the wage structure: evidence from Microdata, 1984-1989', Quarterly Journal of Economics 108(1), 3360 .

Mendonça, R. P. B. \& R. (1995), Bem-estar, pobreza e desigualdade de renda:uma avaliação da evolução histórica e das disparidades regionais, Textos para discussão, IPEA.

Menezes Filho, N. A. (2006), 'Tecnologia e Demanda por Qualificação na Indústria Brasileira', Mimeo.

Menezes Filho, N. A. \& Rodrigues, M. J. (2003), 'Tecnologia e Demanda por Qualificação na Indústria Brasileira', Revista Brasileira de Economia 57(3), 569-603.

Miller, P. \& Mulvey, C. (1997), 'Computer skills and wages', Australian Economic Papers 36(68), 106-113.

Murphy, F. L. K. \& K., M. (1992), 'Changes in Relative Wages, 1963-1987: Supply and Demand Factors', Quartely Journal of Economics 107, 35-72.

Oosterbeek, H. (1997), 'Returns from computers use: a simple test on the productivity interpretation', Economics letters 55(2), 273-277.

Sakkelariou, C. \& Patrinos, H. (2004), 'Technology, computers and wages: evidence from a developing economy', Brussels Economic Review 47(3), 543560. 